\title{
Estudo da interação de diferentes antibacterianos em linhagens de Escherichia coli uropatogênicas
}

\author{
Study of the interaction of different antibacterials in uropathogenic Escherichia coli strains
}

Alana Fernanda Silva de Aquino ${ }^{1}$, Rômulo Maia Ferreira' ${ }^{1}$, Andrea de Souza Monteiro ${ }^{1,2}$, João Luis Damião Caldoncelli

Resumo: A combinação de agentes antimicrobianos disponíveis para o tratamento de infecção do trato urinário causadas por Escherichia coli uropatogênicas tem sido investigada a fim de aumentar a eficácia dos tratamentos. Determinar o perfil de suscetibilidade de isolados uropatogênicas frente a vários antimicrobianos e a eficácia da interação de antimicrobianos. Neste estudo foram avaliadas 39 linhagens de uropatogênicas pelos testes de difusão de antimicrobianos em discos, determinação da concentração inibitória mínima dos antimicrobianos e análise da combinação das drogas antimicrobianas. Os dados obtidos foram submetidos à análise de variância (ANOVA) e as médias comparadas pelo teste de Tukey. As resistências mais significativas foram às classes de tetraciclinas e as cefalosporinas de primeira geração pelo método de disco difusão e sistema VITEK. No método de Checkerboard, a associação entre a cefalotina/norfloxacina e gentamicina/ofloxacina, obtiveram sinergismo em todos os isolados testados. Assim, a associação de antimicrobianos pode ser uma alternativa para o tratamento de infecção do trato urinário, assim como de outras infecções diminuindo a possibilidade de falha terapêutica.

Palavras-chave: Agentes Antibacterianos; Infecções Urinárias; Sinergismo Farmacológico

\begin{abstract}
The association of antimicrobial agents available for the treatment of infection by the causative virus by uropathogenic Escherichia coli has been investigated to increase the volume of treatments. To determine the susceptibility profile of uropathogenic complexities against several antimicrobials and the action of antimicrobial interaction. The present study were evaluated by antimicrobials in three days, analysis of minimum antimicrobial inhibitory activity and antimicrobial drug analysis. Data were obtained by analysis of variance (ANOVA) and the means compared by the Tuckey. The most important resistances were the classes of tetracyclines and the first generation cephalosporins by the diffusion and diffusion method of the VITEK system. In the checkerboard, the association between cephalothin / norfloxacin and gentamicin / ofloxacin, is synonymous with all insects tested. Thus, an association of antimicrobials may be an alternative for the treatment of urinary tract infection, as well as other infections, reducing the possibility of therapeutic failure.
\end{abstract}

Keywords: Anti-Bacterial Agents; Urinary Tract Infections; Drug Synergism

\footnotetext{
${ }^{1}$ Universidade CEUMA, Campus Renascença, Rua dos Castanheiros Jardim Renascença CEP 65075120 São Luís, MA - Brasil, telefone (98) 982869357, endereço eletrônico fernanda.aquino2@hotmail.com.

${ }^{2}$ Faculdade de Ciências da Saúde da Universidade Vale do Rio Doce. Pós-graduação em Ciências Biológicas.
} 


\section{Introdução}

As linhagens bacterianas causadoras de infecções do trato urinário são denominadas Escherichia coli extraintestinais (EXPEC) e dentre elas são classificadas as Escherichia coli uropatogênicas (UPECs). As UPECs apresentam alto grau de virulência e capacidade de formação de microcolônias, ou inclusões conhecidas como comunidades bacterianas intracelulares (IBCs). Estas persistem, principalmente, no interior das células superficiais da bexiga de hospedeiros. Contudo, enquanto os patógenos intestinais são caracterizados por específicos fatores de virulência (VFs), as UPECs permanecem com dados do perfil de virulência bem menos definidos. . $^{1,2,3,4}$

Entretanto, alguns fatores de virulência podem trazer facilidades para a capacidade das UPECs de colonizarem o trato urinário e exercerem efeitos citotóxicos, neste contexto incluem, fímbria tipo 1, fímbria $P$, adesinas, hemolisinas, flagelos, polissacarídeos capsulares, fator 1 necrosante citotóxico, sistemas de transporte de ferro e antígeno $O$ lipopolissacarídeo. As distribuições das propriedades de virulência podem variar dependendo das características do hospedeiro e do tipo de infecção. $^{5}$

As infecções do trato urinário (ITU) são as infeç̧ões mais comuns que acometem os seres humanos, sendo as mais prevalentes infecções associadas ao uso de cateteres hospitalares. As ITUs são causadas principalmente por bacilos Gram-negativos e cerca de 75 a $90 \%$ das uroculturas positivas são de Escherichia coli devido ao local em que essas bactérias se encontram e sua resistência a antibióticos, elas são denominadas como UPEC. 6,7

Um dos fatores mais importantes relacionado a esse tipo de infecção é a capacidade de produção de biofilmes por essas bactérias, pois uma vez, instaladas em superfícies de dispositivos médicos, tais como cateteres e sondas vesicais, elas se desenvolvem nestes objetos, e podem se locomover, até entrarem em contato com o indivíduo, infectando-o. As células bacterianas dos biofilmes destas comunidades produzem exopolissacarídeos extracelulares compostos principalmente de celulose que protegem toda a comunidade contra compostos químicos externos, como por exemplo, agentes antimicrobianos. ${ }^{8,9}$

A combinação de agentes antimicrobianos disponíveis para o tratamento de infecções tem sido investigada a fim de se aumentar a eficácia dos tratamentos. Ás vezes o uso de um único antibiótico não produz os efeitos inibitórios eficazes desejados, mas uma combinação de drogas, muitas vezes exerce um efeito sinérgico que ultrapassa o seu desempenho individual.

$\mathrm{O}$ efeito sinérgico pode ser devido à formação do complexo certo que se torna mais eficaz na inibição de uma espécie particular de micro-organismo, quer por inibição da síntese da parede da célula ou provocando a sua lise ou morte. Com isto, o objetivo deste estudo foi determinar o perfil de suscetibilidade de isolados uropatogênicas frente a vários antimicrobianos e a eficácia da interação de antimicrobianos. ${ }^{10}$

\section{Material e Métodos}

\subsection{Manutenção do isolados de $E$. coliuropatogênicas e testes de difusão de antimicrobianos em discos}

Os isolados bacterianos pertencentes a espécie de $E$. coli foram identificadas inicialmente utilizando as provas bioquímicas contidas no sistema Bactray I e II (LABORCLIN) de acordo com instruções do fabricante. As células dos isolados bacterianos foram estocadas em caldo Brain Heart Infusion (BHI) (Difco, EUA) acrescido de $15 \%$ de glicerol para crioproteção e mantidas congeladas à $-20^{\circ} \mathrm{C}$. 
Para a determinação da sensibilidade e resistência das linhagens, estas foram submetidas ao método de difusão de antimicrobianos em discos em ágar descrito em 1966, por Kirby e Bauer. ${ }^{11}$ Trata-se de um método que fornece resultados qualitativos, cujo princípio é difusão do antimicrobiano na superfície do ágar, com observação de halo de inibição de crescimento microbiano. Para o ensaio, os inoculos das linhagens de $E$. coli foram padronizados à 0,5 na escala de Mcfarland (eq. à 0,5 X $108 \mathrm{UFC} / \mathrm{ml}$ ).

As linhagens foram inoculadas na superfície do ágar Mueller Hinton com auxílio de um swab, após a inoculação os discos com os antimicrobianos, as placas foram incubadas por $24 \mathrm{~h}$ à $35^{\circ} \mathrm{C}$. Após a incubação os diâmetros dos halos de inibição foram medidos e o perfil de susceptibilidade (resistência e sensibilidade) aos antimicrobianos foi então determinado de acordo com as referências do Clinical and laboratory Standards Institute (CLSI) para cada microrganismo analisado. ${ }^{12}$ Os antibacterianos utilizados neste procedimento foram Levofloxacina; Cefalexina; Nitrofurantoina; Aztreonam; Gentamicina; Tobramicina; Tetraciclina; Cloranfenicol, Ácido Nalidíxico; Amicacina; Cefotaxima; Polimixina; Cefepime; Meropenem; Ciprofloxicina e Tetraciclina.

\subsection{Determinação da concentração inibitória mínima dos antimicrobianos em linhagens de E. coliuropatogênicas}

As 39 linhagens de UPECs foram submetidas aos ensaios de confirmação da identidade das espécies, de determinação do perfil de suscetibilidade e concentração inibitória mínima utilizando utilizado os cartões AST №105 e GN-ID para o sistema automatizado VITEK 2 (BioMerieux SA, Marcy-l'Etoile, França). As análises foram feitas de acordo com as recomendações do fabricante.

Ainda, foram realizados testes de micro diluição em caldo utilizando como referência o método descrito no CLSI. ${ }^{13}$ Para os ensaios de micro diluição em caldo, as células dos isolados bacterianos foram crescidas por $18 \mathrm{~h}$ em meio Agar $\mathrm{BHI}$, a 35 ㄷ. Após a incubação as células bacterianas foram diluídas em caldo Mueller Hinton (Difco) na concentração de McFarland ( 1,5x105 UFC/ml), e $10 \mu \mathrm{l}$ foram inoculados nos poços de placas de microdiluição de 96 poços (Kartell, Itália), contendo de 0,0156 a $1024 \mu \mathrm{g} / \mathrm{ml}$ (concentrações em progressão geométrica crescente de razão 2) dos antimicrobianos: ofloxacina, norfloxacina, gentamicina ampicilina, sulfisoxazole e cefalolina, obtidos da Sigma Chemical Corp (St. Louis, MO, EUA),diluídos previamente em ácido dimetil-sulfóxido (DMSO, Sigma) (soluções estoques, de 5000 a $10000 \mu \mathrm{g} / \mathrm{ml}$ ).

Os antimicrobianos foram filtrados em membranas estéreis de 0,22 $\mu \mathrm{m}$ (Milipore, EUA) acopladas a seringas. Após a filtração os antimicrobianos foram diluídos em caldo Mueller Hinton na concentração de trabalho. O volume final do conteúdo dos poços foi de $200 \mu \mathrm{l}$. Após o preparo das placas, estas foram incubadas à $35^{\circ} \mathrm{C}$ por até $24 \mathrm{~h}$. Após a incubação, os poços foram monitorados para a determinação da concentração inibitória mimica (CIM) pelo método visual de crescimento das bactérias.

\subsection{Análise da combinação das drogas antimicrobianas}

A interação sinérgica, antagônica ou indiferente das drogas foi avaliada pelo método do Checkerboard como descrito por Schwalbe (2007). O ponto de corte da concentração inibitória mínima (CIM) dos antimicrobianos, bem como a variação das concentrações foi determinado após $24 \mathrm{~h}$ de incubação das 
linhagens a $35^{\circ} \mathrm{C}$, como descrito no item anterior. ${ }^{14}$

Os resultados foram avaliados mediante análise quantitativa (índice FIC, concentração inibitória fracionada). A concentração inibitória mínima (CIM) das drogas antimicrobianas em combinação foi definida como a menor concentração da associação das drogas que inibe $100 \%$ do crescimento microbiano. Com base ao índice da concentração inibitória fracionada (do inglês Fractional Inhibitory Concentration Index - FIC), as interações das drogas foram classificadas como sinérgicas, indiferentes ou antagônicas. O FICl é definido como a soma dos FICs de cada droga; o FIC é definido como a CIM de cada droga, quando usado em combinação dividida pelo CIM de cada droga, quando usada isoladamente. ${ }^{15}$

\subsection{Análise Estatística}

Quando necessário, os dados obtidos foram submetidos à análise de variância (ANOVA) utilizando o programa Prisma 4.0 software (Jandel Scientific, San Rafael, CA). Os resultados serão expressos em termos da média aritmética de três repetições. As médias serão comparadas pelo teste de Tuckey com 0 nível de significância entre 0,001 a 0,05.

\section{Resultados}

Todas as linhagens testadas pelo Método de Disco Difusão foram sensíveis aos antimicrobianos: meropenem, amicacina, polimixina, aztronam e nitrofurantoína. De uma maneira geral as linhagens de E. coli apresentaram maior resistência ao ácido nalidíxico (23,1\%), a tetraciclina $(20,5 \%)$ e a cefalexina $(15,40 \%)$. Neste estudo foi observado que a que a linhagem E. coli 34 apresentou resistência a um maior número de agentes antimicrobianos testados.

\subsection{Determinação da sensibilidade através da metodologia de Kirby e Bauer.}

Os 39 isolados clínicos E. coli UPEC obtidos por urocultura foram submetidos a ensaios de suscetibilidade a antimicrobianos pelos ensaios de discodifusão. A suscetibilidade das linhagens foi determinada às 15 drogas antimicrobianas e o perfil dos isolados foi indicado na Tabela 1.

Tabela 1. Perfil de suscetibilidade a antimicrobianos pelo método de discodifusão (Kirby-Bauer)

\begin{tabular}{cl}
\hline Linhagens & \multicolumn{1}{c}{ Resistência } \\
\hline $\mathbf{7}$ & CLO, NAL, CIP \\
$\mathbf{8}$ & NAL \\
$\mathbf{9}$ & TET \\
$\mathbf{1 0}$ & LVX, TET, NAL, CIP \\
$\mathbf{1 4}$ & CFE, TET, NAL \\
$\mathbf{1 5}$ & LVX,CFE, NAL, CIP \\
$\mathbf{1 6}$ & TET, CLO \\
$\mathbf{2 0}$ & CFE, TET, NAL \\
$\mathbf{3 3}$ & CFE \\
$\mathbf{3 4}$ & CFE, TET, CLO, NAL, CTX \\
$\mathbf{3 5}$ & TOB, CIP \\
\hline $\mathbf{3 8}$ & TET, CLO, NAL \\
& TOB, CFE, TET, NAL, CTX, \\
\hline
\end{tabular}

O sistema VITEK 2 apresenta como limitação, ensaios de CIM normatizados com concentrações determinadas pelo

The Clinical and Laboratory Standards Institute (CLSI). Estas concentrações são utilizadas para otimizar os resultados de CIM levando em consideração o tratamento clinico. Nos cartões testes são apresentadas concentrações com limite máximo referente ao CIM do agente antimicrobiano para determinadas espécies bacterianas. 
Normatizadas a partir de 0,03125 $\mu \mathrm{g} / \mathrm{ml}$ até $1024 \mu \mathrm{g} / \mathrm{ml}$ para 17 linhagens de E. coli (Tabela 3). Foram testados os antimicrobianos norfloxacina, ofloxacina, sulfisoxazole, cefalotina, ampicilina e gentamicina. O ensaio de CIM para um determinado agente antimicrobiano foi incluído baseando-se no perfil de sensibilidade intermediaria e resistência observados nos ensaios de CIM, utilizando o sistema VITEK 2.

Tabela 2. Perfil de suscetibilidade os isolados e linhagens de E.coli UPEC a diferentes agentes antimicrobianos pelo teste de CIM do sistema VITEK2

\begin{tabular}{cl}
\hline Linhagens & \multicolumn{1}{c}{ Resistência } \\
\hline 4 & CFZ, CFL, SBA, AMP, SUT \\
7 & CIP, NOR, AMP \\
\hline 9 & TET \\
10 & LEV, CIP, TET, NOR \\
13 & CFL \\
14 & CFZ, TET, CFL \\
17 & TET, AMP, SUT \\
20 & CFI, SUT \\
23 & TET, SUT, CFL \\
25 & CFL, SBA, AMP, SUT \\
29 & CFL, SBA, AMP, SUT \\
30 & CIP, CFL, AMP \\
31 & LVX, CIP, NOR, SBA, SUT \\
33 & CFZ, CFL, SBA, AMP \\
& LEV, CAZ, CPM, CTX, CRO, \\
34 & CIP, CFZ, TET, NOR, CFL, \\
& SBA, AMP, SUT \\
37 & CFL \\
\hline 38 & LEV, CFZ, CFL \\
\hline 39 & CFZ \\
\hline
\end{tabular}

Levando em consideração esta limitação, o CIM para alguns agentes antimicrobianos foi determinado com concentrações geometricamente. A ofloxacina foi inserida nos ensaios de CIM por ser uma droga antimicrobiana de escolha para o tratamento de infecções do trato urinário por E. coli. Nos ensaios de determinação da concentração inibitória mínima, o CIM para ofloxacina variou de 0,03125 a $16 \mu \mathrm{g} / \mathrm{ml}$. Nos ensaios de determinação da concentração inibitória mínima, o CIM para ofloxacina variou de 0,03125 a 16 $\mu \mathrm{g} / \mathrm{ml}$ e a cefalotina variou de uma concentração de $0,03125 \mu \mathrm{g} / / \mathrm{ml}$ e finalizando com concentração de 1024 $\mu \mathrm{g} / \mathrm{ml}$.

Os isolados 7, 10 e 34 foram classificados como resistentes de acordo com o padrão definido para a droga pelo CLSI. $O$ isolado 07 apresentou os maiores CIM aos agentes antimicrobianos ofloxacina $(16 \mu \mathrm{g} / \mathrm{ml})$ e gentamicina $(64 \mu \mathrm{g} / \mathrm{ml})$, já a cepa 34 os maiores CIM foram da ofloxacina (16 $\mu \mathrm{g} / \mathrm{ml})$ e da cefalotina $(1024 \mu \mathrm{g} / \mathrm{ml})$. Os isolados 4, 20 e 34 apresentaram um CIM elevado para cefalotina, uma cefalosporina de $1^{\text {a }}$ geração em comparação aos outros isolados testados.

\subsection{Determinação do perfil de suscetibilidade pelo método Checkerboard}

A interação sinérgica, antagônica e indiferente da associação de antimicrobianos frente 14 isolados de $E$. coli UPEC foram determinadas pelo método de Checkerboard (Tabela 4). Os antimicrobianos foram selecionados baseando-se no perfil de resistência encontrado nos testes de CIM por VITEK. Foram selecionados micro-organismos que apresentaram resistência a uma ou mais drogas antimicrobianas.

Os isolados 37 e 38 não foram incluídos neste estudo uma vez que os ensaios de CIM por microdiluição não foi normatizado previamente. O critério de inclusão no estudo de interação entre CFL/NOR foi o perfil de resistência à CFZ (cefalosporina de $1^{\underline{a}}$ geração), à CFL (cefalosporina de $1^{\text {a }}$ geração), à SUT e as FQs NOR e CIP nos ensaios do CIM. 
Tabela 3. Determinação do CIM dos agentes antimicrobianos para os isolados de $E$. coli UPEC

ofloxacina sulfisoxazole gentamicina Cefalotina norfloxacina ampicilina

\begin{tabular}{lcccccc}
\hline \multicolumn{5}{c}{ Concentração $\mu \mathrm{gg} / \mathrm{ml}(\mathrm{CIM})$} \\
$\mathbf{0 4}$ & 0,03125 & 512 & 2 & 256 & 0,063 & 512 \\
$\mathbf{0 7}$ & 16 & 512 & 64 & 64 & 128 & 512 \\
$\mathbf{1 0}$ & 16 & 512 & 2 & 32 & 128 & 2 \\
$\mathbf{1 3}$ & 0,0625 & 1024 & 4 & 0,063 & 0,063 & $\mathrm{ND}$ \\
$\mathbf{1 6}$ & 0,03125 & 512 & 2 & $\mathrm{ND}$ & $\mathrm{ND}$ & 512 \\
$\mathbf{1 7}$ & 0,03125 & 512 & 2 & $\mathrm{ND}$ & $\mathrm{ND}$ & 512 \\
$\mathbf{1 9}$ & 0,03125 & 512 & 2 & $\mathrm{ND}$ & $\mathrm{ND}$ & 8 \\
$\mathbf{2 0}$ & 2 & 512 & 1 & 1024 & 8 & 1024 \\
$\mathbf{2 3}$ & 0,0625 & 1024 & 4 & 16 & 0,125 & $\mathrm{ND}$ \\
$\mathbf{2 5}$ & 0,03125 & 1024 & 2 & 64 & 0,063 & 512 \\
$\mathbf{2 9}$ & 0,03125 & 512 & 2 & 16 & 0,063 & 512 \\
$\mathbf{3 0}$ & 0,0625 & 1024 & 4 & 0,03125 & 0,032 & $\mathrm{ND}$ \\
$\mathbf{3 1}$ & 0,03125 & 512 & 4 & 32 & 0,063 & 512 \\
$\mathbf{3 3}$ & 0,03125 & 512 & 2 & 128 & 0,063 & 1024 \\
$\mathbf{3 4}$ & 16 & 512 & 4 & 1024 & 256 & 1024 \\
$\mathbf{3 9}$ & 0,0156 & 512 & 2 & 0,063 & 0,063 & ND \\
\hline
\end{tabular}

ND-não determinado.

Tabela 4. FICs (Concentração Inibitória Fracionada) para CFL/NOR, GEN/OFL e SUL/OFL em diferentes isolados de E. coli UPEC

\begin{tabular}{|c|c|c|c|c|c|c|c|c|}
\hline \multirow[t]{2}{*}{ Isolados } & \multirow{2}{*}{\multicolumn{2}{|c|}{$\begin{array}{c}\text { Associação de } \\
\text { antimicrobianos }\end{array}$}} & \multirow[t]{2}{*}{ Isolados } & \multirow{2}{*}{\multicolumn{2}{|c|}{$\begin{array}{c}\begin{array}{c}\text { Associação de } \\
\text { antimicrobianos }\end{array} \\
\text { GEN/OFL }\end{array}$}} & \multirow[t]{2}{*}{ Isolados } & \multirow{2}{*}{\multicolumn{2}{|c|}{$\begin{array}{c}\begin{array}{c}\text { Associação de } \\
\text { antimicrobianos }\end{array} \\
\text { SULF/OFL }\end{array}$}} \\
\hline & & & & & & & & \\
\hline 4 & $\mathrm{~S}$ & 0,125 & 7 & $\mathrm{~S}$ & 0,125 & 4 & $A$ & 2,03125 \\
\hline 7 & $\mathrm{~S}$ & 0,125 & 13 & $\mathrm{~S}$ & 0,125 & 16 & $A$ & 2,03125 \\
\hline 13 & $\mathrm{~S}$ & 0,125 & 30 & $\mathrm{~S}$ & 0,125 & 17 & A & 1,03125 \\
\hline 20 & $\mathrm{~S}$ & 0,125 & 31 & $\mathrm{~S}$ & 0,125 & 20 & A & 1,03125 \\
\hline 25 & $\mathrm{~S}$ & 0,125 & 34 & $S$ & 0,125 & 23 & A & 1,03125 \\
\hline 29 & $\mathrm{~S}$ & 0,125 & & & & 25 & A & 2,03125 \\
\hline 30 & $\mathrm{~S}$ & 0,125 & & & & 29 & A & 2,03125 \\
\hline 31 & $\mathrm{~S}$ & 0,125 & & & & 31 & A & 2,03125 \\
\hline 33 & $\mathrm{~S}$ & 0,125 & & & & 34 & $A$ & 1,03125 \\
\hline 39 & $\mathrm{~S}$ & 0,125 & & & & & & \\
\hline
\end{tabular}

CFL: CEFALOTINA; NOR: NORFLOXACINA; GEN: GENTAMICINA; OFL: OFLOXACINA; SULF: SULFISOXAZOLE S: SINERGISMO (FIC: $\leq 0,5)$; A: ANTAGONISMO $(0,5<\mathrm{FIC} \leq 4,0)$ 


\section{Discussão}

Neste estudo, os perfis de resistência observados nos testes de disco de difusão concordaram com observado no sistema VITEK 2. Embora, neste sistema de ensaio não tem sido determinada a concentração inibitória mínima acima da definida pelo (CLSI). Todos os isolados e E. coli testados foram resistentes ao sulfisoxazole, uma sulfonamida antibacteriana com um substituinte oxazole. $O$ sulfisoxazole constitui um dos fármacos de escolha para o tratamento de infecções agudas do trato urinário causadas por bactérias sensíveis, tais como E. coli e Klebsiella spp. ${ }^{12,16}$

Tanto o método por disco-difusão quanto o método automatizado VITEK 2, apresentaram bactérias multidroga resistentes (MDR), sendo este, um problema atual, não só no Brasil como em países desenvolvidos, que leva a um problema expressivo de morbidade, mortalidade e custos hospitalares. O isolado 34 foi detectado como um MDR, e quando a CIM foi determinado para esta linhagem, foi observado uma elevação nos valores da CIM, para os antimicrobianos, ofloxacina, sulfisoxazole, cefalotina, norfloxacina e ampicilina. Recentemente, demonstrouse que as UPECs MDR têm sido reportadas com taxas de resistência, com destaque, aos seguintes antibacterianos, quinolonas $(74,5 \%)$, beta-lactâmicos $(57,4 \%)$ e sulfas $(48,5 \%) .{ }^{18}$

Atualmente, um clone da E. coli , a sequência tipo 131 (ST131), têm sido um isolado MDR associado com aumento da proporção de ITUs e infecções sanguíneas. Sua rápida emergência e propagação relaciona-se a fatores que incluem, resistência as fluorquinolonas, genes altamentes virulentos, presença do alelo Fimh30 para produzir fímbrias do tipo 1 e a produção de CTX-M-15 ESB. Uma importante medida a ser adotada é a racionalização no uso de antimicrobianos, que oferece uma oportunidade de determinar seu apropriado uso nos casos para os quais estão indicados e para que isso acontece se faz necessária a presença de uma atuante comissão de controle de infecção hospitalar. ${ }^{19,17}$

Um dado observado em relação aos antimicrobianos no estudo, foi que tanto no método de disco-difusão, quanto no sistema VITEK 2, todos os isolados de UPECs foram sensíveis a nitrofurantoína, pois este é um antimicrobiano antigo, mas que, atualmente (cefalosporina de $1^{\text {a }}$ geração), à SUT e as FQs NOR e CIP nos ensaios do CIM tem sido largamente empregado no tratamento de ITUs por $E$. coli , pois demonstra ser uma droga com boa atividade e com baixa resistência bacteriana, além de ser indicada para pacientes que fizeram o uso recente de outro antimicrobiano. ${ }^{20,21}$

Quando tratamos da resistência, observamos uma alta taxa em antimicrobianos, como os betalactâmicos, o ácido nalidixico, o sulfametoxazol/trimetoprim, por serem estes a primeira linha de tratamento em ITUs, logo, seus consumos são elevados, demostrando um aumento da resistência em linhagens de UPECs. Tem sido observado que dentre espécie E. coli, várias linhagens vem apresentando um aumento da CIM para tetraciclina, sendo que muitos isolados tem sido caracterizados como resistentes, tanto pelo sistema VITEK como pelo teste de disco-difusão. Acredita-se que esta elevação no nível de resistência pode ser mediada por plasmídeos, que conferem uma menor captação da droga pela bactéria, ainda, algumas bactérias podem ser induzidas a sintetizar enzimas que levam a inativação do antimicrobiano. ${ }^{20,21}$

Neste estudo, avaliando o método do Checkerboard foram observadas interações sinérgicas entre cefalotina e norfloxacina para a 10 linhagens de UPECs testadas, cujo valores foram similares com um índice FIC de 0,125. Ensaios de interação de antimicrobianos em $E$. coli são escassos até o presente 
momento, contudo na literatura foram reportados que associações entre cefalosporinas de terceira geração com ciprofloxacina podem apresentar-se como indiferentes. White e colaboradores $^{22}$ analisando as associações entre cefepime e ciprofloxacina ou cefadizima e ciprofloxacina por ensaios de Checkerboard observaram valores de índices de FIC de 1,00 (indiferente) para as duas associações quando utilizaram a linhagem de E. coli (ATCC 35218).

Entretanto, já foram reportados dados contraditórios sobre a associação de beta-lâctamicos e outros antimicrobianos para outras bactérias Gram negativas, como Pseudomonas aeruginosa e Acinetobacter baumanii. Cefalosporinas, como a ceftazidima, têm apresentado efeito sinérgico in vitro para outras espécies de bactérias quando combinada com outros antimicrobianos. Ao ser testada em pacientes com pneumonias nosocomiais causadas por $P$. aeruginosa, a cefadizima apresentou melhor resultado no controle clínico microbiológico da infecção, quando associada a levofloxacina. A resolução da infecção foi atribuída provavelmente ao efeito sinérgico entre a cefalosporina e a fluorquinolona. ${ }^{22,23}$

Em um outro estudo, realizado em bovinos contra os patógenos Mannheimia haemolytica e de Pasteurella multocida, não foi verificado o efeito sinérgico quando associamos o ceftiofur, uma cefalosporina de terceira geração, com as fluorquinolonas, como o danofloxacina e o enrofloxacina, o efeito apresentado mostrou ser indiferente, efeito este que não quantificamos no presente estudo presente. Um dado interessante, é que tanto as quinolonas como as cefalosporinas, principalmente a ceftazidima, demonstraram efeitos sinérgicos em linhagens de $P$. aeruginosa e $A$. baumannii quando combinadas com a azitromicina. ${ }^{25,26}$

Em outra comparação de efeito de associação, entre colistina e ceftazidima e colistina e ciprofloxacina em um modelo farmacodinâmico, obteve-se resultado sinérgico na primeira associação. Para combinações entre beta-lactâmicos e fluorquinolonas, diferentes interações antimicrobianas tem sido relatadas. Geralmente, sinergismo e antagonismo têm sido reportados, sendo 0 efeito antagônico demonstrado em uma pequena porcentagem de isolados bacterianos. ${ }^{28,29}$

Atualmente, as fluorquinolonas são uma alternativa em relação aos aminoglicosídeos em associações com beta-lactâmicos no tratamento de infecções causadas por bactérias Gramnegativas nosocomiais, por serem menos nefrotóxicas e pela administração oral. Entretanto, Diez- Enciso e colaboradores (1991) avaliaram a associação dos antibacterianos beta-lactâmicos com aminoglicosideos e beta-lactâmicos com fluorquinolonas pelo método de Checkerboard, e observaram uma maior taxa de sinergismo na associação com os aminoglicosídeos. Resultados similares foram observados em outros trabalhos. Neste estudo, foi observado um valor de FIC de 0,125 para associação de gentamicina com ofloxacina para 5 linhagens de E. coli testadas (isolados 7, $13,30,31,34)$, indicando uma interação sinérgica entre os agentes antimicrobianos. ${ }^{30,21,31}$

Uma concordância com esta combinação, onde uma associação tripla, que constituiu um glicipeptidio, vancomicina ou teicoplamina, com levofloxacina, ou aminoglicosídeo ou amicacina, no tratamento de graves infecções respiratórias por $S$. aureus (MRSA), resultou em um efeito sinérgico, sendo que o uso da teicoplamina obteve um melhor resultado. Outro estudo que corroborou com o resultado da associação entre um aminoglicosídeo e as fluorquinolonas, demonstrou sinergismo quando a gentamicina fora associada com algumas fluorquinolonas, entre estas, a ciprofloxacino e a gatifloxacino contra isolados de E. coli. ${ }^{30}$ 
Já Song e colaboradores ${ }^{28}$ utilizando o método de Checkerboard, investigaram que as combinações entre beta-lactâmicos/aminoglicosídeos/flúorqui nolonas tiveram atividade sinérgica contra 24 linhagens de $P$. aeruginosa que são resistentes a esses antimicrobianos, enquanto não foi detectado antagonismo em nenhuma combinação, 0 efeito sinérgico foi observado em uma ou mais de combinações em 15 das 24 linhagens. Também, Bajaksouzian colaboradores $^{34}$, observaram sinergismo para aminoglicosídeos associados com fluorquinolonas contra linhagens quinolona-suscetivéis de $A$. baumannii. ${ }^{28}$ No Japão, investigou-se a atividade da ciprofloxacina associada com a amicacina em 26 linhagens de $P$. aeruginosa isoladas de infecções do trato urinário, concluindo que apenas 1 (uma) destas apresentou o efeito sinérgico, já a combinação entre beta-lactâmicos, especialmente os carbapenêmicos, e as fluorquinolonas mostrou ser a mais adequada. Ensaios associação entre, ampicilina (um beta-lactâmico) com um aminoglicosídeo, a kanamicina, frente a $P$. aeruginosa tem apresentado resultados sinérgicos. ${ }^{35,36}$

$\mathrm{Em}$ ensaios, em que foram utilizados isolados de enterobactérias produtoras de beta-lactamase e $P$. aeruginosa, a combinação da ceftarolina, beta-lactâmico, com levofloxacina apresentou um efeito indiferente para todas as linhagens testadas. Essa cefalosporina com a amicacina demonstrou efeito sinérgico contra $90 \%$ das linhagens utilizada. Comparando com estudos recentes, só que pelo método de Checkerboard, sinergismo foi reportado entre a ceftarolina e amicacina contra uma linhagem de $E$. coli produtora de beta-lactamase, no entanto, na linhagem de $K$. pneumoniae, não foram avaliadas as combinações com amicacina e levofloxacino. ${ }^{37,38}$

No presente estudo, a interação entre sulfisoxazole e ofloxacina foi antagônica, para as 9 linhagens de
UPECs selecionadas, uma vez que os valores de FIC para a associação das duas drogas antimicrobianas foi superior ao índice 0,5 , que é o limite máximo aceitável para uma interação sinérgica. Ainda, foi observado que houve uma variação dos FICs da associação sulfisoxazole e ofloxacina $(1,03125$ e 2,03125). Relatos de associação entre uma sulfa e uma quinolona não são muito comuns na literatura, o que se tem demonstrado mais comumente são a combinações destes com outros antimicrobianos, como por exemplo entre uma quinolona e um beta-lactâmico. Entretanto, interações sinérgicas podem ocorrer quando se associa sulfas e outros antimicrobianos. ${ }^{39}$

Orhan e colaboradores ${ }^{39}$ avaliando combinações de antimicrobianos contra 16 linhagens de Brucella melitensis, testaram 0 efeito da rifampicina com 0 sulfametoxazo-trimetoprim e da doxicilina com 0 sulfametoxazol-trimetoprim, observaram um efeito sinérgico na primeira associação para apenas 1(uma) linhagem, enquanto na segunda, foi relatado o mesmo efeito somente para 4 linhagens. $O$ sulfametoxazol é comumente empregado em associação com o trimetoprim, uma diaminopirimidina, associação mais conhecida como cotrimoxazol. O efeito das duas drogas é sinérgico, pois atuam em passos diferentes da síntese do ácido tetra-hidrofólico (folínico), necessária para a síntese dos ácidos nucléicos. O sulfametoxazol inibe um passo intermediário da reação e o trimetoprim a formação do metabólito ativo do ácido tetra-hidrofólico no final do processo. Um exemplo dessa associação sinérgica é na medicina veterinária no tratamento de meningites por bactérias do grupo coliforme. Outras associações, do trimetoprim, na clínica veterinária são com a sulfonamida e com a sulfadimetoxina, que são utilizados para o tratamento de meningites bacterianas em bovinos e cães. ${ }^{18,40}$ 


\section{Conclusão}

Tanto no método de disco difusão, quanto no método automatizado, utilizando o sistema VITEK, tiveram como resistências mais significativas os antimicrobianos tetraciclinas $e$ as cefalosporinas de primeira geração, cefalexina, no disco difusão e cefalotina, no sistema VITEK. Todas as linhagens testadas foram sensíveis aos antimicrobianos, amicacina, nitrofurantoína e aos carbepenêmicos (meropenem e imipenem).

Houve a detecção de linhagens multirresistentes, no sistema VITEK, cuja característica é a resistência a três ou mais classes de antimicrobianos não relacionadas, nos isolados $04,16,25,29$, 34. Nos ensaios de determinação CIM, por microdiluição em placas de 96 poços, o padrão para as quinolonas (ofloxacino e ciprofloxacino) foram iguais. Nos ensaios de CIM 17 linahgens de UPEC foram resistentes ao sulfisoxazole, uma sulfonamida antibacteriana, na determinação do CIM, por microdiluição em caldo.

Utilizando o método de Checkerboard, para definir o tipo de interação na combinação de antimicrobianos, observou-se uma interação sinérgica em todos os isolados, quando a combinação foi entre a cefalotina e a norfloxacino e entre a gentamicina e o ofloxacino. $\mathrm{Na}$ associação entre sulfisoxazole e ofloxacina, o tipo de interação foi antagônica em todos os isolados.

Destaca-se, com isso, que a combinação entre antimicrobianos tornase uma alternativa que pode ser viável no tratamento de infecções causadas por $E$. coli, sejam elas urinárias ou de qualquer outro foco. No entanto, mais pesquisas e estudos serão necessários para a completa introdução desta metodologia no cenário da saúde, onde possa-se abranger todas as espécies bacterianas e a combinação de todos os antimicrobianos possíveis.

\section{Agradecimentos}

A Professora Vera Lúcia dos Santos da Universidade Federal de Minas Gerais.

\section{Conflito de interesses} interesses.
Este estudo não possui conflito de
esses. 


\section{Referências}

1. Russo TA, Johnson JR, Proposal for a new inclusive designation for extraintestinal pathogenic isolates of E. coli: ExPEC. J. Infect. Dis. 181:1753-1754,2000.

2. Schilling, JD, Mulvey MA, Hultgren SJ. Structure and function of $E$. coli type 1 pili: new insight into the pathogenesis ofurinary tract infections. J. Infect. Dis. 183(Suppl. 1):S36-S40, 2001.

3. Marrs CF, Zhang L, Foxman B. E. coli mediated urinary tract infections: are there distinct uropatogenic $E$. coli(UPEC) pathotypes?. FEMS Microbiol. Lett. 252;183-190,2005.

4. Brzuszkiewicz $E$, Bruggemann $H$, Liesegang $\mathrm{H}$, Emmerth $\mathrm{M}$, Olschlager T, Nagy G, Albermann K, Wagner C, Buchrieser C, Emody L, Gottschalk G, Hacker J, Dobrindt U. How to become a uropathogen: comparative genomic analysis of extraintestinal pathogenic E. coli strains. Proc. Natl. Acad. Sci. USA. 2006; 103:12879-84.

5. Obaid JMAS. Uropathogenic E. coli isolates with different virulence genes content exhibit similar pathologic influence on vero cells. Polish J. Microbiol. 2014; 63(1):43-49.

6. Narciso A, Lito L, Cristino JM, Duarte A. Escherichia coli uropatogênicas. Resistência aos antibióticos versus fatores de virulência. Acta Urol. . 1120. 2010

7. Gupta K. Increasing antimicrobial resistance and the management of uncomplicated comunity-acquired urinary tract infections. Ann. Intern. Med. V. 2001;135(1): 41-50.

8. Culler HF. Formação de biofilme por E. coli Enteropatogênica Atípica. Dissertação de Mestrado em Biotecnologia. São Paulo: Universidade de São Paulo - Instituto de Biotecnologia de São Carlos. 2010.

9. Hultgren SJ, Mysorekar IU. Mechanisms of uropathogenic E. coli persistence and eradication from the urinary tract. PNAS. 2006; 103(38): 14170-175.

10. Chanda S, Rakholya K. Combination therapy: Synergism between natural plant extracts and antibiotics against infectious diseases. Science against microbial. Pathogens: Communicating current research and technological advances. 2011; 1(13): 520-29.

11. Bauer AW, Kirby WM, Sherris JC, Turck $M$. Antibiotic susceptibility testing by a standardized single disk method. Am J Clin Pathol. 1966 Apr;45(4):493-6.

12. Clinical and Laboratory Standards Institute (CLSI). Performance Standards for Antimicrobial Disk Susceptibility Tests. Clinical and Laboratory Standards Institute, WAYNE, P.A.: CLSI,2005

13. Clinical and Laboratory Standards Institute (CLSI). Performance Standards for Antimicrobial Disk Susceptibility Tests. Clinical and Laboratory Standards Institute, WAYNE, P.A.: CLSI,2003

14. Schwalbe R, Steele-moore L, Goodwin AC. Antimicrobial susceptibility testing protocols. Boca Raton: Taylor e Francis, 2007. P.275299.

15. Odds FC. Synergy, antagonism and what the Checkerboard puts between them. J. Antimicrob. Chemother.52(1):1.2003.

16. Hardman J, Limbird L. Goodman \& Gilman. As Bases Farmacológicas da Terapêutica, 10 ed., Rio de Janeiro, MacGraw Hill, 2003.

17. Ribas RM, Filho PGP, Cezario RC, Silva PF, Lanconi DPP, Duque AS. Fatores de risco para colonização por bactérias hospitalares multirresistentes em pacientes críticos e clínicos em um Hospital Universitário Brasileiro. Rev. Med. Minas Gerais, 19(3):193-197,2009.

18. Niranjan V, Malini A. Antimicrobial resistence pattern in $\mathrm{E}$. coli causing urinary tract infection among 
impatients. Indian J. Med. Res. 2014; 139(6): 945-8.

19. ANVISA. Antimicrobianos-

Bases teóricas e uso clínico. 2007

20. Rodrigues TM, Grieco AS, Simoes FA, Castilho LN. Como diagnosticar e tratar infecção urinaria. RBM, vol. 67, 2010.

21. Spinosa HS, Gorniak SL, Bernardi MM. Farmacologia aplicada a medicina veterinária. Editora Guanabara Koogan, Quarta edição,2006.

22. White RL, Burgess DS, Manduru M, Bosso JÁ. Comparison of three different in vitro methods of detecting synergy: Timekill, Checkerboard And E-Test. Antimicrob. Agents Chemother., 40(8): 1914-18, 1997.

23. Jung R, Husain M, Choi MK, Fish DN. Synergistic activies of moxifloxacin combined with piperaciclin-tazobactan or cefepime against Klebisiella pneumonia, Enterobacter cloacae, and Acinetobacter baumannii clinical isolates. Antimicrob. Agents Chemother,2004; 48(3): 1055-1057.

24. Bassetti M, Righi E, Rosso R, Manelli S, Di Biaggio A, Fasce R. Efficacy of the combination of levofloxacinplus ceftazidime in the treatment of hospital-acquired pneumonia in the intensive care unit. Int J. Antimicrob. Agents. 2006;28:582-585.

25. Sweeney MT, Brumbaugh GW, Watts JL. In vitro activies of tulathromycin and ceftiofur combined with other antimicrobial agents using bovine $P$. multocida and $M$. haemolytica isolates. Veterinary Therapeutics. Vol. 9, Number 3, 212-222, 2008.

26. Timurkaynak F, Can F, Azap OK, Demirbilek M, Arslan H, Karaman SO. In vitro activities of non-traditional antimicrobials alone or in combination against multidrug-resistent strain of $P$. aeruginosa and $A$. baumannii isolated from intensive care units. Int. J. Antimicrob. Agents.2006;27:224-228.

27. Gunderson BW, Ibrahim KH, Hovde LB, Fromm TL, Reed MD, Rotschafer
JC. Synergistic activity of colistin and ceftazidime against multiantibioticresistent $P$. aeruginosa in an in vitro pharmacodynamic model. Antimicrob. Agents Chemother.2003;47:905-909.

28. Song W, Woo HJ, Kim JS, Lee KM.. In vitro activity of beta-lactams in combination with other antimicrobial agents against resistant strains of $P$. aeruginosa . Int. J. Antimicrob. Agents. 2003; 21:8-12

29. Davis MA, Isenberg HD, France KA, Jenkings SG. In vitro activity of gatifloxacin alone and in combination with cefepime ,meropenem, piperacilin and gentamicin against multidrug-resistent organisms. J. Antimicrob. Chemother 2003; 51:1203-1211.

30. Drago L, De Vecchi E, Nicola L, Gismondo MR. In vitro evaluation of antibiotics combinations for empirical therapy of suspected methicillin resistant $\mathrm{S}$. aureus severe respiratory infections. BMC Infectious Diseases. 2007; 1 -7.

31. Pillai SK, Moellering RC, Eliopoulos G. Antimicrobial combinations. In: Lorian V, ed. Antibiotics in Laboratory Medicine. 5th ed. Baltimore: Williams \& Wilkins, 365-440., 2005.

32. Diez EM. In vitro activity of aztreonam ,cefotaxim , ceftazidime and imipenem combined with ciprofloxacin against Gram negative bacilli and compared with amikacin combinations against $P$. aeruginosa. Eur. J. Clin. Microbiol. Infect. Dis. 1991;10: 90-92.

33. Iroha IR, Amadi ES, Orji JO, Ogabus $A C$, Oji AE, Esimone CO. The interaction between gentamicin and floroquinolones against ESBL producing clinical isolates of $\mathrm{E}$. coli. Trends in Medial Reseach. 2008; 3 : 90-94.

34. Bajaksouzian S. Activies of levofloxacin, ofloxacin and ciprofloxacin, alone or in combination with amikacin, against acinetobacters as determined by checkerboard and time kill studies. Antimicrob. Agents Chemother 1997;41:1073-1076. 
35. Hayami H, Goto T, Kawahara M. Activies of beta-lactams, fluorquinolones, amikacin and fosfomycinalone and in combination against Pseudomonas aeruginosa isolated from complicated urinary tract infections. J. Infect. Chemother 1999; 5:130-138.

36. Spoorthi NJ, Vishwanatha T, Reena $\mathrm{V}$, Divyashree BC, Aishwarya $\mathrm{S}$, Siddhalingeshwara KG, Venugopal N, Ramesh I. Antibiotic synergy test: Checkerboard method on multidrug resistant Pseudomonas aeruginosa. International Research Journal of Pharmacy.2011,2(12),196-198.

37. Vidaillac C, Leonard SN, Sader HS, Jones RN, Rybak MJ. In vitro activity of ceftaroline alone and in combinations against clinical isolates of resistant gram-negative pathogens , including beta-lactamase-producing Enterobacteriaceae and Pseudomonas aeruginosa. Antimicrob. Agents and Chemotherapy, 2009, p.2360 - 2366.

38. Schaadt RD, Sweeney DA, Biek D, Zurenko GE. In vitro evaluation of the antibacterial activity of ceftaroline in combination with other antibacterial agents, abstr.E-279. Progr. Abstr. 47th Intersci. Conf. Antimicrob.

39. Orhan G, Bayram A, Zer Y, Balci I. Synergy tests by $E$ test and Checkerboard Methods of Antimicrobial Combinations against Brucellamelitensis. J. of Clinical Microb. 2004:vol 43, número 1; 140143.

40. Sweeney MT, Brumbaugh GW, Watts $\mathrm{JL}$. In vitro activies of tulathromycin and ceftiofur combined with other antimicrobial agents using bovine $P$. multocida and $M$. haemolytica isolates. Veterinary Therapeutics. Vol. 9, Number 3, 212-222, 2008. 